\title{
Nintedanib in advanced NSCLC: management of adverse events
}

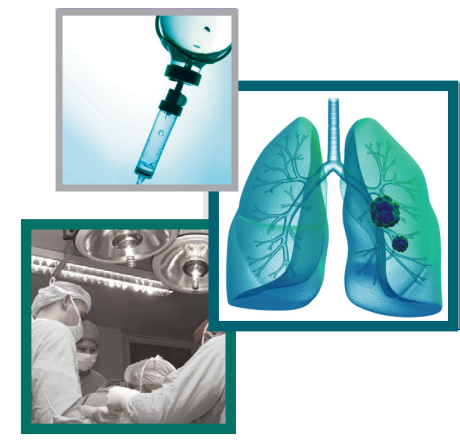

\author{
Liesbeth Lemmens*
}

\section{Practice points}

- Nintedanib plus docetaxel significantly improves survival compared with docetaxel monotherapy in patients with locally advanced, metastatic or locally recurrent NSCLC of adenocarcinoma histology after first-line chemotherapy without detriment to patient's quality of life.

- A review of nintedanib clinical data and the approved prescribing information for use of nintedanib in patients with adenocarcinoma NSCLC provides guidance on managing potential adverse events (AEs) associated with treatment.

- Common AEs include gastrointestinal events and elevated liver enzymes.

- AEs that occur with treatment are generally of mild-to-moderate severity and can typically be dealt with successfully if identified promptly and managed proactively according to pre-specified strategies.

- A clear treatment plan that takes into consideration the individual needs and preferences of each patient is likely to help reduce the burden of $A E s$.

Nintedanib plus docetaxel is approved in the EU for the treatment of patients with locally advanced, metastatic or locally recurrent NSCLC of adenocarcinoma histology after first-line chemotherapy. Nintedanib in combination with docetaxel has a manageable safety profile in adenocarcinoma NSCLC patients. The most frequent adverse events (AEs) associated with nintedanib are gastrointestinal events and elevations in liver enzymes. Most AEs can be managed effectively with supportive treatment or a dose reduction and do not require permanent discontinuation. This article aims to provide practical guidance on management of AEs and how patients should be assessed for AEs prior to initiation and regularly monitored throughout treatment. Patients and their carers can play an important role in recognizing and managing AEs and should be given the relevant information, skills and confidence to achieve this.

Lung cancer is one of the most common cancers and is the leading cause of cancer mortality in the world [1]. Approximately $80 \%$ of patients with lung cancer have NSCLC and they typically present with locally advanced or metastatic disease [2-4]. Standard first-line therapy for the majority of these patients, whose tumors do not have activating EGFR mutations or $A L K$ oncogenes, is a platinumbased chemotherapy doublet with or without the antiangiogenic agent bevacizumab [3,5]. Treatment options for patients who require second-line treatment have remained the same for many years, until recently. Nintedanib (VARGATEF ${ }^{\circledR}$, Boehringer Ingelheim) is a novel, oral agent that is approved in the EU for use in combination with docetaxel to treat locally advanced, metastatic or locally recurrent NSCLC of adenocarcinoma histology, the most common histological subtype, in patients who have progressed on first-line chemotherapy [6,7]. Nintedanib acts as an antiangiogenic agent that blocks the formation of new blood vessels supplying tumors with the nutrients that they need to sustain themselves [8]. Nintedanib inhibits three major receptor classes involved in

*COPE-Unlimited, Kermt-Hasselt, Belgium; Tel.: +32 0 496101965; liesbethlemmens@skynet.be

\section{KEYWORDS}

- adenocarcinoma $\bullet$ adverse events • adverse reactions - diarrhea • increased ALT • increased AST

- neutropenia • nintedanib - NSCLC 
angiogenesis: VEGFR, FGFR and PDGFR [9,10]. The antiangiogenic properties of nintedanib are also under evaluation in patients with other solid tumors, including colorectal cancer [11,12], renal cell carcinoma [13,14] and hepatocellular carcinoma $[15,16]$. In addition, the antifibrotic properties of nintedanib have also led to its approval as monotherapy for the treatment of patients with idiopathic pulmonary fibrosis [17-19].

The LUME-Lung 1 study (NCT00805194; study 1199.13) was the pivotal clinical trial that led to the approval of nintedanib for adenocarcinoma NSCLC in the EU as well as other countries [6,7] (for summary, see Table 1). This largescale, Phase III clinical study demonstrated that nintedanib plus docetaxel significantly prolongs survival compared with docetaxel monotherapy for patients with advanced adenocarcinoma NSCLC who have failed first-line chemotherapy [7]. The same study also demonstrated that nintedanib plus docetaxel has a manageable safety profile and that the survival extension is not achieved at the cost of reduced patient quality of life due to adverse events (AEs) [7,20]. Generally well-tolerated, nintedanib, like all anticancer therapies, is associated with a specific pattern of AEs that can potentially occur in some patients.

It is important that oncology teams are aware of the particular AE profile of a targeted treatment. Careful and close observation of patients by the clinical team can help to identify patients at increased risk of potential AEs during the course of treatment, so that they can be proactively prevented if possible, or identified and managed quickly if they do occur. Failure to recognize $\mathrm{AE}$ symptoms, or to manage them effectively with supportive care, dose reduction or treatment interruption, can result in patients having to discontinue treatment permanently, meaning that they may not receive the full efficacy benefit of the therapy. Oncology nurses play a vital role in preventing, recognizing, reporting and managing AEs, as well as in passing on this knowledge to patients, carers and other members of the healthcare team. Therefore, this article reviews the reported clinical experience with nintedanib in adenocarcinoma NSCLC to date and provides practical guidance on how to manage the AEs associated with this treatment.

\section{Safety \& tolerability in patients with NSCLC}

The LUME-Lung 1 study investigated the safety profile of nintedanib in combination with docetaxel using the Common Terminology Criteria for Adverse Events v3.0 (CTCAE) [7,21,22], which differs slightly from the most recent version (v4.03). The most common AEs observed in the LUME-Lung 1 trial for patients with adenocarcinoma NSCLC are shown in Table 2. The AEs that occurred with nintedanib plus docetaxel more frequently than with placebo plus docetaxel were gastrointestinal (GI) events

\section{Table 1. Summary of the LUME-Lung 1 study: key points.}

\begin{tabular}{|c|c|}
\hline Factor & Details \\
\hline Study design & International, randomized, double-blind, controlled Phase III study \\
\hline Patients & 1300 patients with advanced NSCLC who had progressed after first-line chemotherapy \\
\hline Treatments & $\begin{array}{l}\text { Docetaxel } 75 \mathrm{mg} / \mathrm{m}^{2} \text { by intravenous infusion on day } 1 \text {, plus nintedanib } 200 \mathrm{mg} \text { twice daily orally or } \\
\text { matching placebo on days } 2-21 \text { of a } 21 \text {-day cycle } \\
\text { Treatment cycles were continued until patients experienced unacceptable AEs or disease progression }\end{array}$ \\
\hline $\begin{array}{l}\text { Primary end point: PFS - how } \\
\text { long patients live with the disease } \\
\text { without it getting worse - as } \\
\text { determined by an independent } \\
\text { central review panel }\end{array}$ & $\begin{array}{l}\text { Nintedanib plus docetaxel was found to improve PFS significantly compared with placebo plus } \\
\text { docetaxel in the overall patient population, regardless of histology as well as in patients with } \\
\text { adenocarcinoma histology }\end{array}$ \\
\hline Key secondary end point: OS & $\begin{array}{l}\text { OS was also significantly improved in patients with adenocarcinoma NSCLC } \\
\text { In the total adenocarcinoma population, median OS was greater than } 1 \text { year in the nintedanib } \\
\text { plus docetaxel group and OS was significantly greater than in the placebo plus docetaxel group } \\
\text { (median: } 12.6 \text { vs } 10.3 \text { months; HR: } 0.83 \text { [95\% Cl: } 0.70-0.99] ; \mathrm{p}=0.0359 \text { ) }\end{array}$ \\
\hline 1-year survival probability & $52.7 \%$ in the nintedanib plus docetaxel compared with $44.7 \%$ in the placebo plus docetaxel group \\
\hline 2-year survival probability & $\begin{array}{l}25.7 \% \text { in the nintedanib plus docetaxel group compared with } 19.1 \% \text { in the placebo plus docetaxel } \\
\text { group }\end{array}$ \\
\hline
\end{tabular}


Table 2. Adverse events ${ }^{\dagger}$ of all grades occurring in $\geq 10 \%$ of the patients with adenocarcinoma histology in either treatment arm in the LUME-Lung 1 study.

\begin{tabular}{|c|c|c|c|c|}
\hline \multirow[t]{2}{*}{ Preferred term } & \multicolumn{2}{|c|}{ Nintedanib plus docetaxel, n (\%) } & \multicolumn{2}{|c|}{ Placebo plus docetaxel, n (\%) } \\
\hline & All grades & Grade $\geq 3$ & All grades & Grade $\geq 3$ \\
\hline Any AE & $308(96.3)$ & $243(75.9)$ & $314(94.3)$ & $228(68.5)$ \\
\hline Diarrhea & $139(43.4)$ & $20(6.3)$ & $82(24.6)$ & $12(3.6)$ \\
\hline Decreased neutrophil count & $131(40.9)$ & $116(36.3)$ & $135(40.5)$ & $116(34.8)$ \\
\hline ALT increased & $121(37.8)$ & $37(11.6)$ & $31(9.3)$ & $3(0.9)$ \\
\hline Fatigue & 99 (30.9) & $15(4.7)$ & $98(29.4)$ & $14(4.2)$ \\
\hline AST increased & $97(30.3)$ & $13(4.1)$ & $24(7.2)$ & $2(0.6)$ \\
\hline Nausea & $91(28.4)$ & $3(0.9)$ & $59(17.7)$ & $2(0.6)$ \\
\hline Decreased white blood cell count & $89(27.8)$ & $63(19.7)$ & $94(28.2)$ & $61(18.3)$ \\
\hline Decreased appetite & $75(23.4)$ & $4(1.3)$ & $52(15.6)$ & $5(1.5)$ \\
\hline Vomiting & $62(19.4)$ & $4(1.3)$ & $41(12.3)$ & $2(0.6)$ \\
\hline Alopecia & $56(17.5)$ & $1(0.3)$ & $68(20.4)$ & 0 \\
\hline Dyspnea & $54(16.9)$ & $15(4.7)$ & $52(15.6)$ & $20(6.0)$ \\
\hline Neutropenia & $44(13.8)$ & $38(11.9)$ & $51(15.3)$ & $45(13.5)$ \\
\hline Cough & $42(13.1)$ & $3(0.9)$ & $63(18.9)$ & $2(0.6)$ \\
\hline Pyrexia & $39(12.2)$ & $2(0.6)$ & $47(14.1)$ & $1(0.3)$ \\
\hline Stomatitis & $36(11.3)$ & $4(1.3)$ & $26(7.8)$ & $1(0.3)$ \\
\hline Decreased hemoglobin & $35(10.9)$ & $3(0.9)$ & $46(13.8)$ & $7(2.1)$ \\
\hline Constipation & $22(6.9)$ & 0 & 39 (11.7) & $1(0.3)$ \\
\hline \multicolumn{5}{|c|}{$\begin{array}{l}\text { Bold events are AEs for which the frequency of all-grade AEs for nintedanib plus docetaxel was >15\% with placebo plus docetaxel. } \\
\text { 'Defined according to Common Terminology Criteria for Adverse Events v3.0. } \\
\text { AE: Adverse event; ALT: Alanine aminotransferase; AST: Aspartate aminotransferase. } \\
\text { Reproduced with permission from [7] @ Elsevier (2014). }\end{array}$} \\
\hline
\end{tabular}

(diarrhea, nausea and vomiting) and elevations in liver enzymes (increases in alanine aminotransferase [ALT] and aspartate aminotransferase [AST] levels) [7]. Most of these AEs could be managed effectively with supportive treatment or a dose reduction and did not require permanent discontinuation of treatment, and further details of how to manage these AEs are provided below. In total, $21.6 \%$ of patients in the nintedanib plus docetaxel group and 6.6\% in the placebo plus docetaxel group had at least one dose reduction of nintedanib or placebo.

As expected with a docetaxel-containing regimen, hematological AEs, fatigue and alopecia were commonly reported in both treatment arms in the LUME-Lung 1 study. Rates of these AEs were comparable between the treatment arms, indicating that they were likely to be associated with docetaxel rather than nintedanib. Docetaxel dose reductions were implemented for $16.6 \%$ of patients in the nintedanib plus docetaxel group and $12.3 \%$ in the placebo plus docetaxel group. Adding nintedanib did not affect planned docetaxel dosing and the intensity of docetaxel dosing was similar for the two treatment groups. Guidance on the management of docetaxel-related AEs is beyond the scope of this review, but oncology teams should follow their regular management plans and standard guidance [23,24].

Inhibitors of the VEGF pathway have typically been associated with a number of characteristic AEs, referred to in this review as 'AEs of special interest'. Some of these events are rare but potentially serious and include hypertension, arterial and venous thromboembolism (ATE and VTE), bleeding and GI perforation [25]. The mechanisms that link antiangiogenic agents with these AEs of special interest are not well understood currently. In the LUME-Lung 1 trial, the incidence of mainly mild-to-moderate hypertension (grade 1 or 2) and of VTE events increased slightly with nintedanib plus docetaxel compared with placebo plus docetaxel in patients with adenocarcinoma NSCLC (Table 3) [26]. There was no notable difference of any grade in ATE, bleeding or GI perforation AEs [7]. Nevertheless, given the potentially serious nature of these AEs, specific guidance is provided on their management in this review. Some oral antiangiogenic agents are also associated with a number of characteristic AEs, such as hand-foot skin reaction [25], but the incidence of this event in the LUME-Lung 1 trial was less than $1 \%[26]$. 


\section{Nintedanib dosing}

Nintedanib is provided in capsules at two different dose levels: 100 and $150 \mathrm{mg}$. Both the $100 \mathrm{mg}$ capsule (peach-colored) and the $150 \mathrm{mg}$ capsule (brown), are oblong, soft-gelatin capsules imprinted on one side with the Boehringer Ingelheim company symbol and a number representing the dose strength (100 or $150 \mathrm{mg}$ ). Further details related to nintedanib dosing can be found in Box 1.

\section{- Nintedanib dose modification}

Nintedanib dose interruption, reduction or discontinuation may be required for some patients who experience AEs, depending on the severity and the duration of the event. The general principles for modifying the nintedanib dose are outlined in Figure 1. Temporary interruption of nintedanib is recommended as the initial step for AE management until the specific event has resolved to levels that allow continuation of treatment (to grade 1 or baseline severity) [6]. Nintedanib treatment can then be resumed at a reduced dose. Dose modification is required for any patient who experiences a hematological or nonhematological AE of grade $\geq 3$. There are also specific dose modification criteria for patients who experience the most common AEs of diarrhea (outlined in Table 4), nausea and vomiting (Table 5) or elevated liver enzymes (Table 6). Further guidance on applying dose modification principles for these events is provided in the 'Recommendations for management of AEs with nintedanib' section of this review.

\section{- Interactions between nintedanib \& other drugs}

It is important for the oncology nurse to ask patients about other medications a patient might be taking in order to avoid potential drug-drug interactions (DDIs). Many medications, including anticancer medications such as docetaxel, are metabolized in the body by the CYP450 family of enzymes [27]. Coadministering more than one medication that interacts with CYP450 enzymes could lead to DDIs that cause an increase or decrease in blood levels of a drug and a consequent increase in the risk of toxicity or a reduction in efficacy [27]. However, studies have shown that nintedanib metabolism occurs primarily by enzymes other than CYP450 [28] and, as such, the likelihood of DDIs occurring with nintedanib based on CYP450 metabolism is considered to be low [6]. Indeed, coadministration of nintedanib with docetaxel $\left(75 \mathrm{mg} / \mathrm{m}^{2}\right)$ did not alter the pharmacokinetics of either drug to a relevant extent $[29,30]$.

Nintedanib is a substrate of the P-glycoprotein (P-gp) cell membrane transporter that is involved in elimination of drugs from the body. Coadministration of nintedanib with the

Box 1. Nintedanib dosing.

How to take nintedanib?

- Patients should swallow the capsules whole with water and without chewing or crushing

- Nintedanib capsules should preferably be taken with food - that is, during or immediately before or after a meal; pharmacokinetic studies showed that the amount of nintedanib entering the bloodstream is increased by approximately $20 \%$ when administered after food compared with under fasting conditions

\section{Frequency of administration}

- Nintedanib should be administered every day from day 2 to 21 of a standard 21-day docetaxel treatment cycle

- Critically, nintedanib should not be administered on the same day as chemotherapy (day 1)

- On nintedanib dosing days, patients are recommended to take two nintedanib $100 \mathrm{mg}$ capsules $(200 \mathrm{mg}$ ) twice a day for a total daily dose of $400 \mathrm{mg}$. The two daily doses should be taken approximately $12 \mathrm{~h}$ apart, and at approximately the same two times each day (e.g., morning and evening) to ensure that a steady amount of nintedanib is maintained in the body

\section{What to do in the event of a missed dose?}

- If a patient misses a dose of nintedanib or vomits the dose, administration should resume at the next scheduled time of the recommended dose

- The individual daily doses of nintedanib should not be increased beyond the recommended dose to make up for missed or vomited doses and the recommended maximum daily dose of $400 \mathrm{mg}$ should not be exceeded to avoid any potential overexposure and toxicity issues

Data taken from [6]. 
Table 3. Adverse events ${ }^{\dagger}$ specifically associated with VEGF inhibitors occurring in patients with adenocarcinoma in either treatment arm in the LUME-Lung 1 study.

\begin{tabular}{|c|c|c|c|c|}
\hline \multirow[t]{2}{*}{ Adverse events } & \multicolumn{2}{|c|}{ Nintedanib plus docetaxel $(n=320), n(\%)$} & \multicolumn{2}{|c|}{ Placebo plus docetaxel $(n=333), n(\%)$} \\
\hline & All grades & Grade $\geq 3$ & All grades & Grade $\geq 3$ \\
\hline Bleeding & 35 (10.9) & $4(1.3)$ & $37(11.1)$ & $5(1.5)$ \\
\hline Gastrointestinal perforation & $1(0.3)$ & $1(0.3)$ & $1(0.3)$ & $1(0.3)$ \\
\hline Venous thromboembolism & $9(2.8)$ & $3(0.9)$ & $4(1.2)$ & $2(0.6)$ \\
\hline Arterial thromboembolism & $3(0.9)$ & $3(0.9)$ & $7(2.1)$ & $3(0.9)$ \\
\hline Hypertension & $11(3.4)$ & $1(0.3)$ & $2(0.6)$ & $1(0.3)$ \\
\hline
\end{tabular}

potent P-gp inducer rifampicin, an antibiotic, decreases exposure to nintedanib by $50-60 \%$ compared with nintedanib alone. Conversely, co-administration of nintedanib with the potent P-gp inhibitor ketoconazole, used for treatment of fungal infections, increases patients' exposure to nintedanib by approximately $60-80 \%$ [6] Therefore, patients receiving nintedanib and a potent P-gp inhibitor (e.g., ketoconazole or the antibiotic erythromycin) may experience an increase in exposure to nintedanib and should be monitored closely for AEs [6].

\section{Recommendations for management of AEs with nintedanib}

The role of the oncology nurse is vital to multiple aspects of effective AE management, including patient assessment, symptom recognition and reporting, symptom management, co-ordination with other healthcare providers and supportive care [31]. Studies have shown that empowering and enabling patients to take a more active role in their overall care can play a positive role in the physical, psychological and emotional outcomes of treatment [32]. Educating patients to give them the relevant information, skills and the confidence they need to engage in AE self-management is likely to improve outcomes. Nurses have a good opportunity to develop an effective relationship with the patient and their carers together with other members of the oncology team. This enables them to educate patients more successfully about potential AEs and to encourage patients to identify and communicate their own symptoms. Some patients may minimize the importance of AEs and may even try to conceal the symptoms because they fear this may lead to discontinuation of treatment or a dose reduction/temporary interruption that may reduce the efficacy of their treatment [33]. Oncology nurses can provide reassurance that a dose modification is not a cause for concern and is designed to avoid the need for treatment discontinuation, and gives patients the best chance of gaining benefit from the treatment over the longer term [33].

\section{- Prior to starting nintedanib treatment}

Patients receiving nintedanib plus docetaxel for NSCLC will have progressed on first-line chemotherapy and may still be experiencing AEs as a result of this treatment. Therefore, they should be assessed before starting nintedanib to identify conditions, including AEs, resulting from prior therapy and establish baseline values of certain laboratory values, such as liver enzymes and bilirubin. This information can then help to identify new AEs during the course of nintedanib therapy. By keeping diaries of their nintedanib dosing and symptoms, patients can also help to identify and manage their AEs.

\section{- Managing nintedanib-associated adverse events}

This article details practical management strategies for the two main classes of AEs observed with nintedanib in the LUME-Lung 1 study: GI AEs and elevations in liver enzymes. This guidance can be used to supplement existing management strategies based on experience with other chemotherapies, which will also be applicable. Patients may experience docetaxelrelated AEs, such as the hematological events observed in the LUME-Lung 1 study [7]. Existing management strategies for docetaxel will also apply for patients receiving nintedanib plus docetaxel [34-36]. Oncology teams should also consult the nintedanib prescribing information and package insert carefully prior to initiating treatment [6]. It is important to note that, although patients with NSCLC of all histologies were included in the LUME-Lung 1 study, the data discussed here are for patients with adenocarcinoma NSCLC, in line with the approved indication for nintedanib. Furthermore, all 
recommendations regarding symptom severity grading refer to CTCAE v3.0 that was available at the time of the LUME-Lung 1 study; the most recent version is CTCAE v4.03 [21].

\section{- Gastrointestinal AEs}

GI AEs, such as diarrhea, nausea and vomiting, can be distressing for patients and successful intervention to prevent, manage and treat symptoms can improve patients' quality of life during treatment [37]. GI AEs are a common feature of many oral, targeted anticancer therapies [38]. In particular, agents that target the EGFR or the VEGFR, such as nintedanib, are associated with GI events in patients with NSCLC [7,39]. The mechanism of VEGFR inhibitor-induced GI events is currently unclear. VEGFR inhibitors, including nintedanib, are primarily excreted via the feces Therefore, AEs of diarrhea may be caused by local irritation of the intestinal mucosa due to high levels of drug exposure [38].

\section{Diarrhea}

\section{Incidence}

Diarrhea is graded for severity according to the frequency of bowel movements and the volume of stool output compared with baseline. The specific criteria for each grade according to the CTCAE v3.0 are summarized in Table 4. In the LUME-Lung 1 study, diarrhea was the most frequently reported $\mathrm{AE}$ by patients treated with nintedanib plus docetaxel [7]. The majority of patients who experienced diarrhea had symptoms of mild-to-moderate severity (grades 1 and 2) [7]. In practice, monitoring of diarrhea is partly dependent on patient self-reporting and therefore it is important to establish each patients' definition of diarrhea and its severity, which can differ between individuals.

\section{Prevention}

Prior to initiating treatment, patients' bowel patterns should be established as a baseline that any changes can be measured against [40]. Although not routinely used in oncology practice, stool form scales can provide a useful measure of intestinal function at baseline and throughout treatment [41]. Patients should also be educated on the various signs and symptoms of diarrhea so that they can alert their healthcare professional. Patients need to be aware of the signs and symptoms of rare but potentially serious diarrhea complications that may require urgent attention, such as moderate-to-severe cramping, nausea, vomiting, fever, bleeding or signs of dehydration [42]. Prophylaxis with antibiotics, probiotics or activated charcoal has shown inconsistent results for chemotherapy-treated patients [43] and there is insufficient evidence at present to recommend these for patients receiving targeted therapies [44].

\section{Reactive management}

Table 4 provides an overview of considerations for diarrhea management and treatment. Diarrhea should be treated, as soon as it is observed, with antidiarrheal medication (e.g., loperamide) and adequate hydration [40,45]. For grades 1 and 2 diarrhea patients can prevent dehydration by consuming approximately 21 of fluid per day, including some fluids containing sugar or salt to avoid hyponatremia and hypokalemia caused by electrolyte loss [40]. For more severe diarrhea, plasma levels of electrolytes should be monitored by blood sampling and electrolytes and intravenous fluids provided if necessary $[6,42]$.

Patients with grades 1 and 2 diarrhea should be encouraged to eat small meals regularly (e.g., every $2-3 \mathrm{~h}$, six- to 8 -times a day) to ensure adequate nutrition. Foods that can reduce the frequency of bowel movements include bananas, oats, plain white rice and pasta. Foods and drinks that could exacerbate diarrhea should be avoided, such as lactose- or caffeine-containing products, greasy or spicy foods or foods with a high fiber content that are difficult to digest, including wholegrain foods, broccoli and onions. Diet and sugar-free products containing the sweeteners sorbitol or mannitol can cause diarrhea and should also be avoided.

Nintedanib dose modifications in response to diarrhea are guided by the severity grading of symptoms [6]. Dose modification is needed for patients with diarrhea of grade $\geq 2$ severity that persists for more than seven consecutive days despite antidiarrheal treatment, diarrhea of grade $\geq 3$ severity that persists despite antidiarrheal treatment or earlier if required by the individual patient. In these cases, nintedanib treatment should first be stopped temporarily until symptoms recover to grade 1 or baseline levels. Nintedanib can then be restarted at a reduced dose of $150 \mathrm{mg}$ twice daily (Figure 1). Patients who experience a second episode of diarrhea that requires dose modification should stop treatment again and restart at a further reduced dose of $100 \mathrm{mg}$ twice daily. Patients should permanently 
discontinue nintedanib if they experience diarrhea requiring a further dose modification at the $100 \mathrm{mg}$ twice daily dose.

\section{Nausea \& vomiting}

Incidence

Severity grading for nausea is dependent on patients' eating habits and the impact on hydration and nutrition levels, whereas grading of vomiting relates to the frequency of episodes. The criteria for each grade are summarized in Table 5. In the LUME-Lung 1 trial, the majority of patients who experienced nausea and vomiting had symptoms of mild-to-moderate severity (grades 1 and 2) [7].

\section{Prevention}

Patients can manage their risk of nausea and vomiting by adjusting their eating patterns to a greater number of smaller meals throughout the day, and to choose foods and drinks that they can best tolerate. Certain strong odors can trigger symptoms and patients should be encouraged to avoid these. Studies suggest that mint and ginger can be effective, natural antiemetics $[46,47]$ and they may have preventive benefits when taken as a tea or in capsule form.

\section{Reactive management}

If nausea and vomiting do occur, the symptoms should be managed as soon as possible. Medicinal interventions include antiemetic agents, such as glucocorticoids, anti-histamines or $5-\mathrm{HT}_{3}$ receptor antagonists, and these should be used in line with existing guidelines for nausea/vomiting management within the oncology team $[48,49]$.
As with symptoms of diarrhea, it is important to ensure that patients with nausea and vomiting remain adequately hydrated and are regularly monitored for dehydration and plasma electrolyte imbalances. Electrolytes and intravenous fluids should be provided if necessary. Patients who vomit after taking their nintedanib medication should not make up for the vomited dose but should resume treatment at the next scheduled time, at the recommended dose.

Nintedanib dose modifications are required for patients with vomiting grade $\geq 2$ or nausea grade $\geq 3$ that persists despite antiemetic treatment or according to individual patient needs. Treatment should be temporarily interrupted and restarted once symptoms return to baseline or grade 1 at $150 \mathrm{mg}$ twice daily in the first instance and at $100 \mathrm{mg}$ twice daily if a second dose reduction is required (Figure 1). Permanent discontinuation of nintedanib should be considered for patients with nausea or vomiting requiring a further dose modification at the $100 \mathrm{mg}$ twice daily dose [6].

\section{- Elevated liver enzymes \& bilirubin}

Liver enzyme and bilirubin elevations may be an early signal of hepatotoxicity - injury to the liver that can lead to impairment of liver function and, later, symptoms related to liver failure. Liver enzyme elevations are usually asymptomatic but symptoms such as yellow skin and dark urine may occur as a result of elevations in bilirubin [50]. The mechanism by which nintedanib may lead to elevated liver enzymes is currently unknown. Oncology nurses can help to advise patients of the harmful consequences of elevated

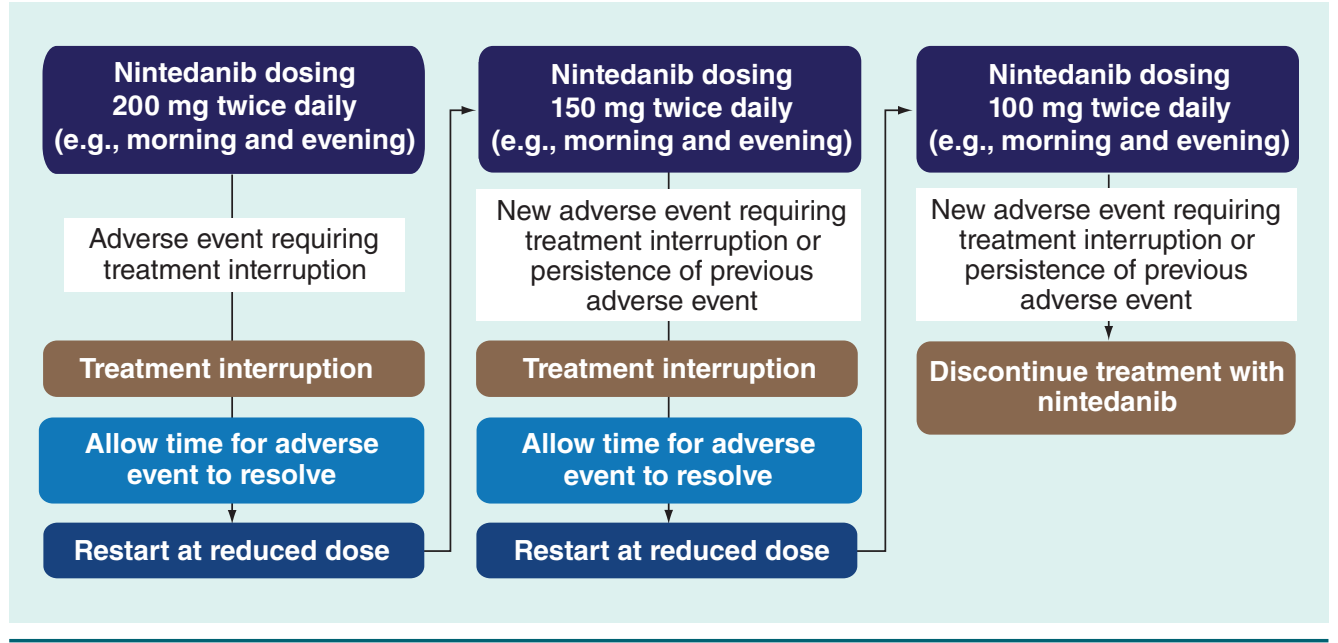

Figure 1. Nintedanib dose-reduction scheme. 
liver enzymes and explain the importance of the periodic liver enzyme tests.

\section{Incidence}

It is important for oncology nurses to have some familiarity with the severity grading used in the assessment of liver enzyme and bilirubin elevations (Table 6). The most commonly reported liver enzyme elevations in patients of adenocarcinoma tumor histology receiving nintedanib in combination with docetaxel in LUME-Lung 1 were elevated AST (30.3\%) and elevated ALT $(37.8 \%)$ levels [7]. The majority of the cases of elevated AST/ALT were grades 1-2 (Table 2). Although liver enzyme elevations were the most common reason for dose reductions in LUMELung 1, most of the increases in liver enzyme levels associated with nintedanib are reversible.

\section{Prevention}

Unlike other frequent AEs, there are no guidelines specific to managing liver enzyme elevations with targeted therapy in oncology. Table 6 provides an overview of the considerations for managing ALT/AST and bilirubin elevation associated with nintedanib therapy. Levels of liver enzymes and bilirubin should be measured before initiation of nintedanib treatment. The values should then be monitored as clinically indicated or periodically during treatment, for example, at the beginning of each cycle for patients undergoing combination therapy with docetaxel, or monthly if docetaxel is discontinued and patients continue on nintedanib monotherapy; more frequent monitoring being advisable for patients with risk factors for hepatic impairment. It should be noted that nintedanib is not recommended for patients with moderate or severe hepatic impairment. Patients should also be asked and counseled about risk factors for liver impairment (e.g., alcohol abuse, obesity, exposure to industrial toxins or hepatitis viruses), and educated on the importance of avoiding excessive alcohol consumption and over-the-counter medications that may affect liver function including paracetamol (acetaminophen) or certain herbal or dietary supplements, such as Kava Kava root, green tea extracts or Chinese natural medicine [45,51].

\section{Reactive management}

The management of elevated AST/ALT levels is based on severity (Table 6). It is recommended

Table 4. Diarrhea: assessment and management.

\begin{tabular}{|c|c|}
\hline Prevention & $\begin{array}{l}\text { - Patient education including dietary advice } \\
\text { - Adequate fluid intake }\end{array}$ \\
\hline \multicolumn{2}{|c|}{ Symptom severity ${ }^{\dagger}$ : } \\
\hline - Grade 1 & $\begin{array}{l}\text { - Increase of }<4 \text { stools per day over baseline; mild increase in ostomy output } \\
\text { compared with baseline }\end{array}$ \\
\hline - Grade $2^{\ddagger}$ & $\begin{array}{l}\text {-Increase of 4-6 stools per day over baseline; iv. fluids indicated }<24 \mathrm{~h} \text {; moderate } \\
\text { increase in ostomy output compared with baseline; not interfering with ADL }\end{array}$ \\
\hline - Grade $3^{\S}$ & $\begin{array}{l}\text { - Increase of } \geq 7 \text { stools per day over baseline; incontinence; iv. fluids } \geq 24 \mathrm{~h} \text {; } \\
\text { hospitalization; severe increase in ostomy output compared with baseline; } \\
\text { interfering with ADL }\end{array}$ \\
\hline - Grade 4" & - Life-threatening consequences (e.g., hemodynamic collapse) \\
\hline - Grade 5 & - Death \\
\hline \multirow{2}{*}{$\begin{array}{l}\text { Reactive } \\
\text { management }\end{array}$} & - As soon as observed: \\
\hline & $\begin{array}{l}\text { - Loperamide ( } 4 \mathrm{mg} \text { ) after first stool and } 2 \mathrm{mg} \text { after every stool, until } 12 \mathrm{~h} \text { after the } \\
\text { last watery stool - maximum dose } 12-16 \mathrm{mg} / \text { day } \\
\text { - Adequate fluid intake } \\
\text { - Consider iv. fluids and electrolyte replacement for } \geq \text { grade } 3\end{array}$ \\
\hline $\begin{array}{l}\text { Nintedanib dose } \\
\text { interruption } \\
\text { required }\end{array}$ & $\begin{array}{l}\text { - Diarrhea } \geq \text { grade } 2 \text { for }>7 \text { consecutive days despite antidiarrheal treatment } \\
\text { or } \\
\text { - Diarrhea } \geq \text { grade } 3 \text { despite antidiarrheal treatment }\end{array}$ \\
\hline \multicolumn{2}{|c|}{ 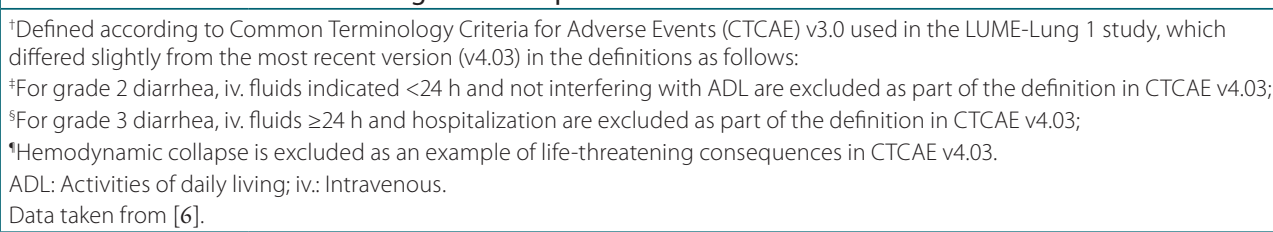 } \\
\hline
\end{tabular}


Table 5. Nausea and vomiting: assessment and management.

\begin{tabular}{|c|c|}
\hline Prevention & $\begin{array}{l}\text { - Patient education including dietary advice } \\
\text { - Mint or ginger taken as a tea or capsule }\end{array}$ \\
\hline \multicolumn{2}{|l|}{ Nausea severity ${ }^{\dagger}$ : } \\
\hline - Grade 1 & - Loss of appetite without alteration in eating habits \\
\hline - Grade $2^{\ddagger}$ & $\begin{array}{l}\text { - Oral intake decreased without significant weight loss, dehydration or } \\
\text { malnutrition; iv. fluids indicated }<24 \mathrm{~h}\end{array}$ \\
\hline - Grade $3^{\S}$ & $\begin{array}{l}\text { - Inadequate oral caloric or fluid intake; iv. fluids, tube feedings or TPN indicated } \\
\geq 24 \mathrm{~h}\end{array}$ \\
\hline - Grade 4 & - \\
\hline - Grade 5 & - \\
\hline \multicolumn{2}{|l|}{ Vomiting severity ${ }^{\dagger}$ : } \\
\hline - Grade $1^{\pi}$ & -1 episode in $24 \mathrm{~h}$ \\
\hline - Grade $2^{\#}$ & $-2-5$ episodes in $24 \mathrm{~h}$; iv. fluids indicated $<24 \mathrm{~h}$ \\
\hline - Grade $3^{+\dagger}$ & $-\geq 6$ episodes in $24 \mathrm{~h}$; iv. fluids, or TPN indicated $\geq 24 \mathrm{~h}$ \\
\hline - Grade $4^{\ddagger \neq}$ & - Life-threatening consequences \\
\hline - Grade 5 & - Death \\
\hline $\begin{array}{l}\text { Reactive } \\
\text { management }\end{array}$ & $\begin{array}{l}\text { - Antiemetic supportive care: } \\
\text { - Glucocorticoids; anti-histamines or 5-HT3 receptor antagonists } \\
\text { - Adequate fluid intake }\end{array}$ \\
\hline $\begin{array}{l}\text { Nintedanib dose } \\
\text { interruption } \\
\text { required }\end{array}$ & $\begin{array}{l}\text { - Vomiting } \geq \text { grade } 2 \\
\text { and/or } \\
\text { - Nausea } \geq \text { grade } 3 \text { despite antiemetic treatment }\end{array}$ \\
\hline \multicolumn{2}{|c|}{$\begin{array}{l}\text { 'Defined according to Common Terminology Criteria for Adverse Events (CTCAE) v3.0 used in the LUME-Lung } 1 \text { study, which } \\
\text { differed slightly from the most recent version (v4.03) in the definitions as follows: } \\
\text { FFor grade } 2 \text { nausea, iv. fluids indicated }<24 \mathrm{~h} \text { is excluded as part of the definition, as per CTCAE v4.03; } \\
\text { \$For grade } 3 \text { nausea, iv. fluids and TPN indicated } \geq 24 \mathrm{~h} \text { are excluded as part of the definition, as per CTCAE 4.03; } \\
\text { 'Grade } 1 \text { vomiting is defined as } 1-2 \text { episodes (separated by } 5 \mathrm{~min} \text { ) in } 24 \mathrm{~h} \text {; } \\
\text { "Grade } 2 \text { vomiting is defined as } 3-5 \text { episodes (separated by } 5 \mathrm{~min} \text { ) in } 24 \mathrm{~h} \text {; } \\
{ }^{+} G \text { Grade } 3 \text { vomiting is defined as } \geq 6 \text { episodes (separated by } 5 \mathrm{~min} \text { ) in } 24 \mathrm{~h} \text {; tube feeding, TPN or hospitalization indicated; } \\
\text { f\#Grade } 4 \text { vomiting is defined as life-threatening consequences; urgent intervention indicated. } \\
\text { iv.: Intravenous; TPN: Total parenteral nutrition. } \\
\text { Data taken from [6]. }\end{array}$} \\
\hline
\end{tabular}

that nintedanib treatment be interrupted in patients with AST and/or ALT elevations $>2.5 \times$ ULN in conjunction with total bilirubin elevations $\geq 1.5 \times$ ULN or AST and/or ALT elevations $>5 \times$ ULN [6]. In such cases, alternative causes of AST/ALT elevation should also be investigated and appropriate action taken as necessary. Nintedanib treatment can be resumed at a reduced dose when AST/ALT enzyme values return to $\leq 2.5 \times \mathrm{ULN}$ in conjunction with bilirubin to normal [6]. For patients with AST and/or ALT elevations $>3 \times \mathrm{ULN}$ in conjunction with elevated bilirubin $\geq 2 \times$ ULN in the absence of elevated alkaline phosphatase levels $(<2 \times \mathrm{ULN})$, nintedanib treatment should be permanently discontinued unless an alternative cause of liver damage can be established.

\section{AEs of special interest}

Oncology teams should be mindful of the possibility for rare but potentially serious AEs that are characteristic of angiogenesis inhibitors, including ATE and VTE, bleeding, impaired wound healing and GI perforation [25]. Guidance on managing the risk of these events is provided here. The frequency of patients experiencing hypertension with nintedanib plus docetaxel was low and the reported AEs were mainly of CTCAE grade 1 and 2 (Table 3). Hypertension that does occur should be managed in line with existing guidelines [52].

\section{- Bleeding \& wound healing \\ Incidence}

In the LUME-Lung 1 study, bleeding was more frequent in the nintedanib arm of the overall population compared with the placebo arm driven by between-treatment differences in patients with squamous cell carcinoma NSCLC. In adenocarcinoma patients, the incidence of bleeding was similar in the two treatment groups (placebo: 11.1\%, nintedanib: 10.9\%). Mild-to-moderate epistaxis represented the most frequent bleeding events. There were no 
imbalances of respiratory bleedings. Based on its mechanism of action, nintedanib may impair wound healing, although no increased frequency of impaired wound healing was observed in the LUME-Lung 1 study.

\section{Prevention \& management}

Patients with recent pulmonary bleeding ( $>2.5 \mathrm{ml}$ of red blood), as well as patients with centrally located tumors with radiographic evidence of local invasion of major blood vessels or radiographic evidence of cavitary or necrotic tumors, were excluded from nintedanib clinical trials. Therefore, nintedanib is not recommended in these patients [6]. Patients taking concomitant anticoagulation therapy, such as warfarin or phenprocoumon, should be monitored regularly for changes in prothrombin time, international normalized ratio and clinical bleeding episodes [6]. Patients should be educated on the importance of highlighting immediately any evidence of major bleeding to the oncology team. As a precaution, nintedanib should only be initiated or, in the case of perioperative interruption, resumed in patients who have wounds that are adequately healed based on clinical judgement [6]. Nintedanib should be interrupted in patients requiring surgery until wounds are adequately healed, based on clinical judgment [6].

\section{- Arterial \& venous thromboembolism Incidence}

Nintedanib was associated with a slight increase in VTE, including deep vein thrombosis compared with placebo, in the LUME-Lung 1 study [7]. Nintedanib was not associated with an increase in ATE AEs compared with placebo. Patients with a recent history of myocardial infarction or stroke were excluded. A slightly increased frequency of patients with ATE has been seen with nintedanib monotherapy in clinical trials of patients with idiopathic pulmonary fibrosis.

\section{Prevention \& management}

Caution should be exercised when treating patients with a higher cardiovascular risk, including known coronary artery disease. Nintedanib should be discontinued in patients with lifethreatening VTE reactions. Treatment interruption should also be considered in patients who develop signs or symptoms of acute myocardial ischemia [6]. Patients should be educated on the signs and symptoms of VTE (e.g., pain, swelling, reddening, warmth of a limb) and ATE (chest pressure or pain, pain in the neck, jaw, shoulder or arm, a fast heartbeat, shortness of breath, and nausea and vomiting) and of the importance of highlighting these to their oncology nurse or treating physician [6]. Thromboembolic events should be managed according to local treatment guidelines.

\section{- Gl perforation}

\section{Incidence}

Nintedanib was not associated with an increased frequency of patients with GI perforations compared with placebo in the LUME-Lung 1 study [7]. However, as with the risk of bleeding, the mechanism of action of nintedanib may increase the risk of GI perforations.

\section{Prevention \& management}

Particular caution should be exercised when treating patients with previous abdominal surgery. Nintedanib should only be initiated at least 4 weeks after major surgery. Nintedanib should be permanently discontinued in patients who develop GI perforations [6]. Patients should alert the oncology team immediately if they experience symptoms corresponding with GI perforation, such as severe abdominal pain, fever, chills, sickness, vomiting, or abdominal rigidity or bloating [6].

\section{Future perspective}

Nintedanib in combination with docetaxel has been shown to be effective and has a manageable safety profile for patients with adenocarcinoma NSCLC who progressed following first-line chemotherapy [7]. A clear treatment plan that takes into consideration the individual needs and preferences of each patient is likely to help to reduce the burden of AEs. When they do occur, most AEs associated with nintedanib are of mild-to-moderate severity, and can generally be dealt with successfully if they are identified promptly and managed proactively according to pre-specified strategies. Preventing AEs from escalating to more serious events will improve outcomes for patients and reduce the burden of treatment over the longer term. Thorough examination prior to initiating nintedanib and regular monitoring throughout the course of treatment is important and will help the potential of this treatment option to be realized. Educating and involving patients and their carer in symptom monitoring and management will help to 
Table 6. Liver enzyme and bilirubin elevations: assessment and management.

\begin{tabular}{|c|c|c|c|c|}
\hline \multirow[b]{2}{*}{ Symptom severity ${ }^{+}$: } & \multicolumn{4}{|c|}{$\begin{array}{l}\text { - Monitoring prior to initiation, periodically throughout treatment and as } \\
\text { clinically indicated } \\
\text { - Assessment of concomitant medication } \\
\text { - Patient education on risk factors }\end{array}$} \\
\hline & AST & ALT & ALKP & Bilirubin \\
\hline - Grade $1^{\ddagger}$ & $>1-2.5 \times$ ULN & $>1-2.5 \times$ ULN & $>1-2.5 \times$ ULN & $>1-1.5 \times$ ULN \\
\hline - Grade $2^{\ddagger}$ & $>2.5-5 \times$ ULN & $>2.5-5 \times$ ULN & $>2.5-5 \times$ ULN & $>1.5-3 \times$ ULN \\
\hline - Grade 3 & $>5-20 \times$ ULN & $>5-20 \times \mathrm{U}$ & $>5-20 x$ & $\mathrm{~N}$ \\
\hline 4 & $>1-3$ & $>1-3$ & $>1$ & \\
\hline - Gra & - & - & 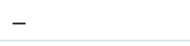 & - \\
\hline $\begin{array}{l}\text { ctive } \\
\text { nagement }\end{array}$ & \multicolumn{4}{|c|}{$\begin{array}{l}\text { - Investigate potential alternative causes of AST/ALT elevation other than } \\
\text { nintedanib and take action as necessary }\end{array}$} \\
\hline $\begin{array}{l}\text { Nintedanib dose } \\
\text { nterruption } \\
\text { equired }\end{array}$ & \multicolumn{4}{|c|}{$\begin{array}{l}\text { - Elevation of AST and/or ALT values to }>2.5 \times \text { ULN in conjunction with total } \\
\text { bilirubin elevation to } \geq 1.5 \times \text { ULN } \\
\text { or } \\
\text { - Elevation of AST and/or ALT values to }>5 \times \text { ULN }\end{array}$} \\
\hline $\begin{array}{l}\text { Nintedanib } \\
\text { discontinuation } \\
\text { required }\end{array}$ & \multicolumn{4}{|c|}{$\begin{array}{l}\text { - Elevation of AST and/or ALT values to }>3 \times \text { ULN in conjunction with an increase } \\
\text { of total bilirubin to } \geq 2 \times U L N \text { and ALKP }<2 \times \text { ULN }\end{array}$} \\
\hline \multicolumn{5}{|c|}{$\begin{array}{l}\text { Defined according to Common Terminology Criteria for Adverse Events (CTCAE) V3.0 in the LUME-Lung } 1 \text { study, which differed } \\
\text { slightly from the most recent version (v4.03) in the definitions as follows: } \\
\text { For grade } 1 \text { ALT/AST elevation the upper limit was } 3.0 \times \text { ULN and for grade } 2 \text { ALT/AST elevation the lower limit was >3.0 XULN } \\
\text { according to the definitions in CTCAE v4.03. } \\
\text { ALT: Alanine aminotransferase; AST: Aspartate aminotransferase; ALKP: Alkaline phosphatase; CTCAE: ; ULN: Upper limit of normal. } \\
\text { Data taken from [6]. }\end{array}$} \\
\hline
\end{tabular}

identify AEs earlier and may facilitate faster AE improvement. Greater patient and carer involvement is also likely to have the added benefit of improving satisfaction by fostering a sense of empowerment over their treatment. Through concerted effort from the oncology team, the patient and wider healthcare services, the AEs of nintedanib can be effectively managed and the need for dose modification minimized to give patients the best chance of gaining benefit from treatment.

\section{Acknowledgements}

The author gratefully acknowledges the assistance of Soetkin Vlassak, Kerstin Möldner and Pouya Pakneshan (Boehringer Ingelheim) for critical review of the manuscript before submission.

\section{Financial \& competing interests disclosure}

L Lemmens is a consult for Boehringer Ingelheim, Amgen and Novartis. The author has no other relevant affiliations or financial involvement with any organization or entity with a financial interest in or financial conflict with the subject matter or materials discussed in the manuscript apart from those disclosed.

Medical writing assistance was provided by Huw Jones and Suzanne Patel (inVentiv Health, London, UK) during preparation of this report and was supported financially by Boehringer Ingelheim.

\section{Open access}

This work is licensed under the Creative Commons Attribution-NonCommercial 4.0 Unported License. To view a copy of this license, visit http://creativecommons.org/ licenses/by-nc-nd/4.0/

\section{References}

Papers of special note have been highlighted as:

- of interest; $\bullet \bullet$ of considerable interest

1 World Health Organization: International Agency for Research on Cancer. GLOBOCAN 2012: Estimated cancer incidence, mortality and prevalence worldwide in 2012 (2012). http://globocan.iarc.fr/
2 Morgensztern D, Ng SH, Gao F, Govindan $\mathrm{R}$. Trends in stage distribution for patients with non-small cell lung cancer: a National Cancer Database survey. J. Thorac. Oncol. 5(1), 29-33 (2010).

3 National Comprehensive Cancer Network. NCCN Clinical Practice Guidelines in Oncology (NCCN Guidelines): Non-Small
Cell Lung Cancer. Version 4 (2015). www.nccn.org

-• Frequently updated guidelines providing latest insights into the management of NSCLC.

4 Peters S, Adjei AA, Gridelli C et al. Metastatic non-small-cell lung cancer (NSCLC): ESMO Clinical Practice 
Guidelines for diagnosis, treatment and follow-up. Ann. Oncol. 23(Suppl. 7), vii56-vii64 (2012).

5 Reck M, Popat S, Reinmuth $\mathrm{N}$ et al. Metastatic non-small-cell lung cancer (NSCLC): ESMO Clinical Practice Guidelines for diagnosis, treatment and follow-up. Ann. Oncol. 25(Suppl. 3), iii27-iii39 (2014).

- The most recent European Society for Medical Oncology guidelines for the treatment of NSCLC.

$6 \quad$ Boehringer Ingelheim. Vargatef ${ }^{\circledR}$ (nintedanib) summary of product characteristics (2014). http://ec.europa.eu

- The full prescribing information with detailed information on the tolerability profile of nintedanib and guidance on management of adverse events.

7 Reck M, Kaiser R, Mellemgaard A et al. Docetaxel plus nintedanib versus docetaxel plus placebo in patients with previously treated non-small-cell lung cancer (LUME-Lung 1): a Phase 3, double-blind, randomised controlled trial. Lancet Oncol. 15(2), 143-155 (2014).

- Full results of the pivotal study that led to the approval of nintedanib plus docetaxel in the EU for the treatment of patients with locally advanced, metastatic or locally recurrent NSCLC of adenocarcinoma histology after first-line chemotherapy.

8 Lee CP, Taylor NJ, Attard G et al. A Phase I study of BIBF 1120, an orally active triple angiokinase inhibitor (VEGFR, PDGFR, FGFR) given continuously to patients with advanced solid tumours, incorporating dynamic contrast enhanced magnetic resonance imaging (DCE-MRI). J. Clin. Oncol. 24(18S), 3015 (2006).

9 Hilberg F, Roth GJ, Krssak M et al. BIBF 1120: triple angiokinase inhibitor with sustained receptor blockade and good antitumor efficacy. Cancer Res. 68(12), 4774-4782 (2008).

10 Roth GJ, Heckel A, Colbatzky F et al. Design, synthesis, and evaluation of indolinones as triple angiokinase inhibitors and the discovery of a highly specific 6-methoxycarbonylsubstituted indolinone (BIBF 1120). J. Med. Chem. 52(14), 4466-4480 (2009).

11 Van Cutsem E, Prenen H, Guillen-Ponce C et al. A Phase I/II, open-label, randomised study of BIBF 1120 plus mFOLFOX6 compared with bevacizumab plus mFOLFOX6 in patients with metastatic colorectal cancer. Eur. J. Cancer 47 8-9 (2011).

12 Van Cutsem E, Tabernero J, Yoshino T et al. LUME-Colon 1: double-blind, randomised
Phase III study of nintedanib plus best supportive care (BSC) versus placebo plus BSC in patients with refractory colorectal cancer. Ann. Oncol. 25 (Suppl 4), iv208 (2014).

13 Eisen T, Shparyk Y, Jones R et al. Phase II efficacy and safety study of nintedanib versus sunitinib in previously untreated renal cell carcinoma (RCC) patients. J. Clin. Oncol. 31, Abstract 4506 (2013).

14 Eisen T, Shparyk Y, Macleod N et al. Effect of small angiokinase inhibitor nintedanib (BIBF 1120 ) on QT interval in patients with previously untreated, advanced renal cell cancer in an open-label, Phase II study. Invest. New Drugs 31(5), 1283-1293 (2013).

15 Palmer D, Peck-Radosavljevic M, Ma YT et al. Open-label, Phase I/randomized Phase II trial of the triple angiokinase inhibitor, nintedanib, versus sorafenib in previously untreated patients with advanced hepatocellular carcinoma (HCC). J. Clin. Oncol. 31(Supp), Abstract TPS4160 (2013).

16 Yen C, Kim TY, Feng YH et al. Efficacy and safety of nintedanib vs sorafenib in Asian patients with advanced hepatocellular carcinoma (HCC): a randomised Phase II trial. Eur. J. Cancer 49, S612 (2013).

17 US Food and Drug Administration. FDA approves Ofev to treat idiopathic pulmonary fibrosis (2012). www.fda.gov

18 Richeldi L, Du Bois RM, Raghu G et al. Efficacy and safety of nintedanib in idiopathic pulmonary fibrosis. N. Engl. J. Med. 370(22), 2071-2082 (2014).

19 European Medicines Agency. Summary of opinion (initial authorisation): Ofev (nintedanib) (2014). www.ema.europa.eu

20 Novello S, Kaiser R, Mellemgaard A et al. Analysis of patient-reported outcomes from the LUME-Lung 1 trial: a randomised, double-blind, placebo-controlled, Phase III study of second-line nintedanib in patients with advanced non-small cell lung cancer. Eur. J. Cancer 51(3), 317-326 (2015).

21 US National Cancer Institute. Common Terminology Criteria for Adverse Events (CTCAE) v4.03 (2010). http://evs.nci.nih.gov

22 US National Cancer Institute. Common Terminology Criteria for Adverse Events (CTCAE) v3.0 (2006). http://ctep.cancer.gov

23 Baker J, Ajani J, Scotte F et al. Docetaxelrelated side effects and their management. Eur. J. Oncol. Nurs. 13(1), 49-59 (2009).
24 Cheville AL, Kollasch J, Vandenberg J et al. A home-based exercise program to improve function, fatigue, and sleep quality in patients with stage IV lung and colorectal cancer: a randomized controlled trial. J. Pain Symptom Manage. 45(5), 811-821 (2013).

25 Chen HX, Cleck JN. Adverse effects of anticancer agents that target the VEGF pathway. Nat. Rev. Clin. Oncol. 6(8), 465-477 (2009).

- A comprehensive review of adverse events commonly associated with agents that target the VEGF pathway including discussion of the potential mechanisms by which they occur.

26 Reck M, Mellemgaard A, Von Pawel J et al. Anti-angiogenic-specific adverse events in patients with non-small cell lung cancer treated with nintedanib and docetaxel. Lung Cancer doi: 10.1016/j.lungcan.2015.08.003 (2015) (Epub ahead of print).

- A detailed report of the adverse event profile of nintedanib in combination with docetaxel.

27 Song X, Varker H, Eichelbaum M et al. Treatment of lung cancer patients and concomitant use of drugs interacting with cytochrome P450 isoenzymes. Lung Cancer 74(1), 103-111 (2011).

28 Stopfer P, Rathgen K, Bischoff D et al. Pharmacokinetics and metabolism of BIBF 1120 after oral dosing to healthy male volunteers. Xenobiotica 41(4), 297-311 (2011).

29 Bousquet G, Alexandre J, Le Tourneau C et al. Phase I study of BIBF 1120 with docetaxel and prednisone in metastatic chemo-naive hormone-refractory prostate cancer patients. Br. J. Cancer 105(11), 1640-1645 (2011).

30 Okamoto I, Miyazaki M, Takeda M et al. Tolerability of nintedanib (BIBF 1120) in combination with docetaxel: a Phase 1 study in Japanese patients with previously treated non-small-cell lung cancer. J. Thorac. Oncol. 10(2), 346-352 (2015).

31 Rieger PT, Yarbo CH. Role of the Oncology Nurse. In: Cancer Medicine. Kufe DW, Pollock RE, Weichselbaum RR et al. (Eds). BC Decker Hamilton, ON, Canada (2003).

32 McCorkle R, Ercolano E, Lazenby M et al. Self-management: Enabling and empowering patients living with cancer as a chronic illness. CA Cancer J. Clin. 61(1), 50-62 (2011).

33 Pyle L, Andersen E, Langan C, Mathew A, Pitfield D, Stretch A. Side effects of pazopanib in renal cell carcinoma. Cancer Nurse Practice 11(3), 16-22 (2012).

34 Aapro MS, Bohlius J, Cameron DA et al. 2010 update of EORTC guidelines for the use 
of granulocyte-colony stimulating factor to reduce the incidence of chemotherapyinduced febrile neutropenia in adult patients with lymphoproliferative disorders and solid tumours. Eur. J. Cancer 47(1), 8-32 (2011).

35 Curigliano G, Cardinale D, Suter T et al. Cardiovascular toxicity induced by chemotherapy, targeted agents and radiotherapy: ESMO Clinical Practice Guidelines. Ann. Oncol. 23(Suppl. 7), vii155-vii166 (2012).

Leonard K. A European survey relating to cancer therapy and neutropenic infections: nurse and patient viewpoints. Eur. J. Oncol. Nurs. 16(4), 380-386 (2012).

37 Bender CM, McDaniel RW, Murphy-Ende K et al. Chemotherapy-induced nausea and vomiting. Clin. J. Oncol. Nurs. 6(2), 94-102 (2002).

38 Bowen JM. Mechanisms of TKI-induced diarrhea in cancer patients. Curr. Opin. Support. Palliat. Care 7(2), 162-167 (2013).

39 Xiao YY, Zhan P, Yuan DM et al. Chemotherapy plus multitargeted antiangiogenic tyrosine kinase inhibitors or chemotherapy alone in advanced NSCLC: a meta-analysis of randomized controlled trials. Eur. J. Clin. Pharmacol. 69(2), 151-159 (2013).
40 Benson AB 3rd, Ajani JA, Catalano RB et al. Recommended guidelines for the treatment of cancer treatment-induced diarrhea. J. Clin. Oncol. 22(14), 2918-2926 (2004).

41 Lewis SJ, Heaton KW. Stool form scale as a useful guide to intestinal transit time. Scand. J. Gastroenterol. 32(9), 920-924 (1997).

42 Cherny NI. Evaluation and management of treatment-related diarrhea in patients with advanced cancer: a review. J. Pain Symptom Manage. 36(4), 413-423 (2008).

43 Stein A, Voigt W, Jordan K. Chemotherapyinduced diarrhea: pathophysiology, frequency and guideline-based management. Ther. Adv. Med. Oncol. 2(1), 51-63 (2010).

44 Pessi MA, Zilembo N, Haspinger ER et al. Targeted therapy-induced diarrhea: a review of the literature. Crit. Rev. Oncol. Hematol. 90(2), 165-179 (2014).

45 Fischer-Cartlidge EA. Assessment and management of gastrointestinal toxicities and lab abnormalities related to targeted therapy. Semin. Oncol. Nurs. 30(3), 183-189 (2014).

46 Lee J, Oh H. Ginger as an antiemetic modality for chemotherapy-induced nausea and vomiting: a systematic review and meta-analysis. Oncol. Nurs. Forum 40(2), 163-170 (2013).
47 Tayarani-Najaran Z, Talasaz-Firoozi E, Nasiri R, Jalali N, Hassanzadeh M. Antiemetic activity of volatile oil from Mentha spicata and Mentha $\times$ piperita in chemotherapy-induced nausea and vomiting. Ecancermedicalscience 7 , 290 (2013).

48 Roila F, Herrstedt J, Aapro M et al. Guideline update for MASCC and ESMO in the prevention of chemotherapy- and radiotherapy-induced nausea and vomiting: results of the Perugia consensus conference. Ann. Oncol. 21(Suppl. 5), 232-243 (2010).

49 Tipton JM, McDaniel RW, Barbour L et al. Putting evidence into practice: evidencebased interventions to prevent, manage, and treat chemotherapy-induced nausea and vomiting. Clin. J. Oncol. Nurs. 11(1), 69-78 (2007).

50 Kee JLF, Hayes ER, McCuistion LE. Targeted therapies to treat cancer. In: Pharmacology: A Patient-Centered Nursing Process Approach. Elsevier - Health Sciences Division, 530-553 (2014).

51 Bjornsson ES. Drug-induced liver injury: an overview over the most critical compounds. Arch. Toxicol. 89(3), 327-334 (2015).

52 Suter TM, Ewer MS. Cancer drugs and the heart: importance and management. Eur. Heart J. 34(15), 1102-1111 (2013). 